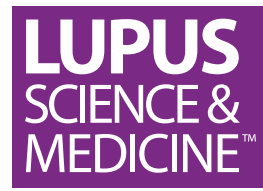
Learning to listen: how empathetic engagement with patients can help overcome reproductive injustice. Lupus Science \& Medicine 2020;7:e000455. doi:10.1136/ lupus-2020-000455

Received 2 November 2020 Accepted 3 November 2020

Check for updates

(C) Author(s) (or their employer(s)) 2020. Re-use permitted under CC BY-NC. No commercial re-use. See rights and permissions. Published by BMJ.

Medicine, Duke University, Durham, North Carolina, USA

Correspondence to

Dr Megan E B Clowse; megan. clowse@duke.edu

\title{
Learning to listen: how empathetic engagement with patients can help overcome reproductive injustice
}

\author{
Megan E B Clowse
}

Dialogue for paper: Anti-Müllerian Hormone in African American Women with Systemic Lupus Erythematosus

Reproductive justice stands at the intersection of social justice and reproductive health, where it focuses attention on the reproductive health and rights of women who suffer social injustices.

Although a pilot study of a hormone may seem an unlikely springboard for a serious discussion about this subject, I believe that the watershed events of 2020 suggest that adding such a lens is essential to the health and lives of our patients. It is possible that relatively few rheumatologists view themselves at the forefront of this movement. However, by working empathetically and using the recent American College of Rheumatology's Reproductive Health Guidelines, rheumatologists can help black women overcome some of the reproductive injustice they currently suffer.

This pilot study by Angley and colleagues, ${ }^{1}$ published in this issue of Lupus Science $\mathcal{E}^{\circ}$ Medicine, demonstrates that black women with SLE, both without and especially with prior cyclophosphamide (CYC) therapy, have significantly lower levels of antimullerian hormone (AMH) than black women without SLE. AMH is steadily generated by existing ovarian follicles, which means that measuring its levels can provide a rough estimate of ovarian reserve, or the number of potential eggs a woman has left to produce. It can be predictive of early menopause; in addition, women with lower levels of $\mathrm{AMH}$ are less likely to conceive. ${ }^{2}{ }^{3} \mathrm{~A}$ recent meta-analysis-one that included very few black women-demonstrated that women with SLE, and especially those with prior CYC therapy, have lower levels of $\mathrm{AMH}^{4}$ than other women.

The small subgroup of women in this study who had received prior CYC for their SLE was particularly affected: despite being significantly younger than the other women in the study, $70 \%$ of them had AMH levels below the 25th percentile of age-adjusted women without SLE. In a separate investigation in the same cohort of patients, this subgroup had an increased incidence of infertility compared with other women with SLE. ${ }^{5}$ Interestingly, however, women with SLE had similar number of pregnancies and live births and there was no difference seen in the frequency of infertility when the woman was actively trying to conceive. I suspect that this was largely driven by the young age of pregnancy in women with SLE, whose average age was 20 years (compared with 24 years in the control group), meaning that many women had their pregnancies prior to the onset of SLE.

Coupled with the study of infertility in the same population, this study provides an important opportunity to think about health equity in the context of reproductive health for women with SLE. These results suggest that with or without CYC, our patients are at higher risk for premature menopause, which comes with significant cardiovascular and osteoporotic risk. It also implies the importance of discussing long-term fertility with patients with SLE. Conception in the later 30s may be particularly challenging for these women, who expressed the same desire for a family as did healthy women, with only $3 \%$ of either group reporting not wanting children and both groups wanting a median of two children. Denying a family to women with SLE, particularly when it can be achieved relatively safely for both the mother and the infant, can be considered an issue of social justice-the more so when some patients are disproportionately affected. Recent studies suggest that adverse pregnancy outcomes such as preterm birth and pre-eclampsia are more common in women of colour. ${ }^{67}$ Further analysis of the PROMISSE study demonstrates that social determinants of health, particularly a lower level of community educational 
attainment, were perhaps more strongly associated with poor pregnancy outcomes than race, and not overcome by monthly visits to rheumatologists and/or obstetricians with expertise in lupus. ${ }^{8}$

Better inclusion of black women living with SLE in clinical research is an essential element of working to achieve health equity in this vulnerable population. The Georgians Organized Against Lupus (GOAL) study, from which the present study is derived, has demonstrated that a diagnosis of SLE places black women at even higher risk for poor medical outcomes that are sensitive to systemic racism and social determinants of health. ${ }^{9}$ For example, black women diagnosed with SLE are more likely to be unemployed. The GOAL authors also demonstrate that experiencing racism, whether inside and outside of the medical setting, is associated with increased SLE activity and/or damage. The lived experience of young black women with SLE is clearly different from that of many of the women with SLE who are typically enrolled in trials and observational studies. Identifying and testing approaches that we as rheumatologists can use to help counter some of the prevailing challenges these women face are essential if we are to be effective as physicians.

This body of work demands that we continue to identify innovative approaches that can improve pregnancy safety for women with SLE, with particular focus on women at risk for poor outcomes that can be modulated by a range of social determinants of health. I suggest that one key to this is to openly and empathetically address a woman's desire for pregnancy. ${ }^{1011}$ Such an approach likely seems both simple and obvious; nevertheless, it does not appear to happen routinely in rheumatic care. ${ }^{12} 13$ Broaching the topic with open-ended questions about a woman's future interest in pregnancy can begin a dialogue that is informative to both the woman (who may assume that her rheumatologist will not want her to conceive) and to the rheumatologist (who may assume that a woman with SLE may not want to have children). This study of AMH by Angley and colleagues ${ }^{1}$ can further inform this discussion: for black women with SLE, whether they have received CYC or not, it is important to consider that their window for pregnancy may be more limited than for other women. While infertility may not be reduced overall, delaying conception too long may prevent them from having the family that they want.

Acknowledgements The author thanks Jonathan McCall, MS, for editorial assistance in the preparation of this manuscript.
Contributors $\mathrm{MC}$ composed this manuscript in response to a request from $\mathrm{Dr}$ Buyon.

Funding The authors have not declared a specific grant for this research from any funding agency in the public, commercial or not-for-profit sectors.

Competing interests Grant funding from GSK; consultant for UCB, GSK and AstraZeneca.

Patient and public involvement Patients and/or the public were not involved in the design, or conduct, or reporting, or dissemination plans of this research. Patient consent for publication Not required.

Provenance and peer review Commissioned; internally peer reviewed.

Open access This is an open access article distributed in accordance with the Creative Commons Attribution Non Commercial (CC BY-NC 4.0) license, which permits others to distribute, remix, adapt, build upon this work non-commercially, and license their derivative works on different terms, provided the original work is properly cited, appropriate credit is given, any changes made indicated, and the use is non-commercial. See: http://creativecommons.org/licenses/by-nc/4.0/.

\section{ORCID iD}

Megan E B Clowse http://orcid.org/0000-0002-8579-3470

\section{REFERENCES}

1 Angley M, Spencer JB, Lim SS, et al. Anti-müllerian hormone in African-American women with systemic lupus erythematosus. Lupus Sci Med. In Press 2020;7:e000439.

2 Finkelstein JS, Lee $\mathrm{H}$, Karlamangla A, et al. Antimullerian hormone and impending menopause in late reproductive age: the study of women's health across the Nation. J Clin Endocrinol Metab 2020;105:e1862-71.

3 Bertone-Johnson ER, Manson JE, Purdue-Smithe AC, et al. AntiMüllerian hormone levels and incidence of early natural menopause in a prospective study. Hum Reprod 2018;33:1175-82.

4 Luo W, Mao P, Zhang L, et al. Assessment of ovarian reserve by serum anti-Müllerian hormone in patients with systemic lupus erythematosus: a meta-analysis. Ann Palliat Med 2020;9:207-15.

5 Angley M, Lim SS, Spencer JB, et al. Infertility among African American women with systemic lupus erythematosus compared to healthy women: a pilot study. Arthritis Care Res 2020;72:1275-81.

6 Clowse MEB, Grotegut C. Racial and ethnic disparities in the pregnancies of women with systemic lupus erythematosus. Arthritis Care Res 2016;68:1567-72.

7 Buyon JP, Kim MY, Guerra MM, et al. Predictors of pregnancy outcomes in patients with lupus: a cohort study. Ann Intern Med 2015;163:153-63.

8 Kaplowitz ET, Ferguson S, Guerra M, et al. Contribution of socioeconomic status to racial/ethnic disparities in adverse pregnancy outcomes among women with systemic lupus erythematosus. Arthritis Care Res 2018;70:230-5.

9 Lim SS, Drenkard C. Understanding lupus disparities through a social determinants of health framework: the Georgians organized against lupus research cohort. Rheum Dis Clin North Am 2020;46:613-21.

10 Clowse MEB, Eudy AM, Revels J, et al. Provider perceptions on the management of lupus during pregnancy: barriers to improved care. Lupus 2019;28:86-93.

11 Njagi P, Arsenijevic J, Groot W. Cost-related unmet need for healthcare services in Kenya. BMC Health Serv Res 2020;20:322.

12 Clowse ME, Eudy AM, Revels J, et al. Rheumatologists' knowledge of contraception, teratogens, and pregnancy risks. Obstet Med 2018;11:182-5

13 Birru Talabi M, Clowse MEB, Blalock SJ, et al. Perspectives of adult rheumatologists regarding family planning counseling and care: a qualitative study. Arthritis Care Res 2020;72:452-8. 